\title{
Bioavailability of phthalate congeners to earthworms (Eisenia fetida) in artificially contaminated soils
}

\author{
Xiao-yu Hu, Bei Wen, Shuzhen Zhang, Xiao-quan Shan* \\ State Key Laboratory of Environmental Chemistry and Ecotoxicology, Research Center for Eco-Environmental Sciences, \\ Chinese Academy of Sciences, P.O. Box 2871, Beijing 100085, China
}

Received 10 November 2004; received in revised form 22 February 2005; accepted 26 February 2005

Available online 3 May 2005

\begin{abstract}
Bioavailability of phthalate congeners, dimethyl phthalate, diethyl phthalate, di-n-butyl phthalate (DBP), di-(2-ethylhexyl) phthalate (DEHP), and dioctyl phthalate, to earthworms (Eisenia fetida) were studied when earthworms were exposed to two artificially contaminated agricultural and forest soils. Only DBP and DEHP were detected in earthworms. The uptake kinetics of DBP and DEHP in earthworms was fast within the initial 10 days followed by a nearly steady state for the subsequent 20 days. An equilibrium partitioning model could be used to describe the uptake kinetics of DBP and DEHP by earthworm in two types of soils $(r=0.709-0.864)$. The average biota-to-soil accumulation factors (BSAFs) of DBP and DEHP at $5 \mathrm{mg} \mathrm{kg}^{-1}$ in soil were $0.27 \pm 0.07$ and $0.17 \pm 0.03$, respectively, in agricultural soil, while the BSAFs were $0.21 \pm 0.06$ and $0.07 \pm 0.02$, respectively, in forest soil. The concentrations of phthalates in earthworms increased with increasing concentrations of phthalates in soil. There was a significant correlation between $\log C_{\text {soil }}$ and $\log C_{\text {worm }}$, with $r=0.999-0.993$, demonstrating a single linear partitioning of phthalates between soil and earthworms. The bioavailability of DBP and DEHP was assessed by Soxhlet, methanol, and methanol-water (1:1) extraction methods. Our results indicated that the extractable amounts of freshly added DBP and DEHP in soils by these extraction methods were significantly correlated with those in earthworms. It was observed that the extractable DBP and DEHP by the methanol and methanol-water (1:1) extraction methods decreased with their increasing residence time in soil. In contrast, the amount extracted by the Soxhlet extraction method did not show a similar decline. Therefore, Soxhlet extraction was a poor indicator of the bioavailability of DBP and DEHP to earthworms in soil, which could lead to overestimation of the risk of soilassociated DBP and DEHP. The extractable DBP and DEHP by methanol and methanol-water (1:1) significantly decreased over 440 days. Compared with the methanol-water (1:1) extraction method, the methanol extraction method was preferred for its ability to predict the bioavailability of DBP and DEHP in aged soils.
\end{abstract}

(C) 2005 Elsevier Inc. All rights reserved.

Keywords: Bioavailability; Phthalates; Earthworms; Soil; Equilibrium partitioning model

\section{Introduction}

Earthworms comprise the largest part of the soil fauna biomass and are able to accumulate various organic contaminants, including chlorinated hydrocarbons (Morrison et al., 2000), polychlorinated biphenyls (Krauss et al., 2000), and polycyclic aromatic hydrocarbons (Kelsey and Alexander, 1997), etc. Accumula-

\footnotetext{
${ }^{*}$ Corresponding author. Fax: + 861062923563 .

E-mail address: xiaoquan@mail.rcees.ac.cn (X.-q. Shan).
}

tion of organic contaminants implies a risk not only to earthworm populations but also to many vertebrate species feeding on earthworms. Therefore, earthworms are considered standard soil toxicity test organisms and are suitable for assessing the bioavailability of many chemicals in the soil environment (Lanno et al., 2004).

Bioavailability is a measure of a chemical for entry into a biological receptor. It is specific to the receptor, the route of entry, the time of exposure, and the matrix containing the contaminant (Anderson et al., 1999). Therefore, when assessing the bioavailability of soil 
contaminants, it is crucial to study the uptake kinetics of these chemicals in organisms. To describe the uptake kinetics of organic compounds in soils or sediments, the equilibrium partitioning theory, initially proposed by Shea (1989) and further developed by DiToro et al. (1991), has frequently been applied (Connell and Markwell, 1990). It presumes that the uptake kinetics of organic chemicals in soil- and sediment-dwelling organisms is usually described as a simple hydrophobic partitioning process between pore water and lipids of the organisms. The theory has been validated for a number of soil- or sediment-dwelling organisms (Belfroid et al., 1996).

There is considerable evidence that the exposure of various organisms to organic compounds in soil is overestimated by the use of vigorous extraction methods (Kelsey and Alexander, 1997). The reason for this is that not all of the compounds removed from soil by these extraction procedures are available to soil organisms. The bioavailability of this soil pool depends on soil chemical and physical properties (Nam et al., 1998). The bioavailability decreases with increasing residence time ("aging effect") of the compounds in soil or sediment, and such decreases differ among various organic contaminants (Kelsey and Alexander, 1997). Considering that bioassays of bioavailability are time consuming and expensive, it is essential to develop a simple method, a mild chemical extraction procedure, as a surrogate of bioassays to assess bioavailable pools (Kelsey et al., 1997; Tang et al., 1999).

Phthalate pollution is of global concern due to their widespread occurrence and endocrine-disrupting properties (Wezel et al., 2000; $\mathrm{Hu}$ et al., 2003). The continuous release of large quantities of phthalates into the environment remains a substantial threat to ecosystems and human health. However, there is little information on the bioavailability of phthalates to earthworms (Staples et al., 1997). Since bioavailability constitutes an ecological risk and is an indispensable part of a complete risk assessment of chemicals, it is worth investigating the bioavailability of soil-associated phthalates to earthworms.

In the present study, five phthalate congeners, dimethyl phthalate (DMP), diethyl phthalate (DEP), di-n-butyl phthalate (DBP), di-(2-ethylhexyl) phthalate (DEHP), and dioctyl phthalate (DNOP), all recognized as priority pollutants by the US Environmental Protection Agency (Environmental Protection Agency (EPA), 2002), were chosen as representatives of phthalate congeners to evaluate the effect of the physicochemical properties of test compounds on their bioavailability in soils. The earthworms studied were Eisenia fetida, a standard organism recommended by the Organization for Economic Cooperation and Development (OECD, 1984) for tests of acute and subacute toxicity of soilassociated pollutants. The objectives of the present study were to evaluate whether the equilibrium partitioning model could describe the uptake kinetics of phthalates in artificially contaminated soil by earthworms, to assess the relationship between different concentrations of phthalates in different soils and those in earthworms, to investigate the aging effect on the extractability and bioavailability of phthalates in soil, and to test the feasibility of a mild chemical extraction for estimating bioavailability of phthalates in soil.

\section{Materials and methods}

\subsection{Soils}

Two Chinese agricultural and forest soils (S1 and S2) collected from Beijing were used in the trial. The soils were air-dried, ground, and screened through a 1-mm nylon fiber sieve to remove stones, plant roots, and other large particles. Soil $\mathrm{pH}$ was measured in deionized water using a soil/solution ratio of 1:1 (w:v). Organic matter content was determined by the Walkley-Black procedure (Nelson and Sommers, 1982). Cation exchange capacity was determined by the method described by Rhoades (1982). Different amounts of phthalates were added dropwise to the soils as a dichloromethane solution and mixed thoroughly using a high-speed mixer (Waring blender). Autoclaved distilled water was added to give a moisture content of $40 \%$ water holding capacity (WHC). The spiked soils were then transferred to solvent-rinsed microcosms (3-kg Kilner jar). To each microcosm, $1.5 \mathrm{~kg}$ of the spiked soil was added, sealed, and then immediately sterilized with $2.5 \mathrm{Mrad}$ of gamma irradiation from ${ }^{60} \mathrm{Co}$. After sterilization, the microcosms were incubated at $20^{\circ} \mathrm{C}$ for different time intervals. Over the course of this study, the jars were sealed and stored in the dark to prevent phthalates loss through volatilization and/or photodegradation over the period of incubation. The accuracy and homogeneity of the spiking and the concentrations of phthalate congeners after aging were evaluated by analyzing six subsamples as described below.

\subsection{Uptake of phthalates}

Earthworms (E. fetida), purchased from the Agricultural University of China (Beijing, China), were maintained in moistened uncontaminated soil S1 $(40 \%$ WHC) using organic-free reagent water. Before Experiment 1, the phthalate contents in earthworms were determined.

Experiment 1. The uptake kinetics of soil-associated phthalates by earthworms. Phthalates were added to soils $\mathrm{S} 1$ and $\mathrm{S} 2$ to give final concentrations of $5 \mathrm{mg} \mathrm{kg}^{-1}$. Three hundred earthworms (total weight $74,000 \pm 300 \mathrm{mg}$ ) were exposed to the two artificially 
contaminated soils separately from 5 to 30 days. At the 5th, 10th, 15th, 20th, and 30th day, worms were sampled to study the uptake kinetics. To minimize stress and disturbance to the worm collection, 10 worms were kept as a group in 1000-ml glass beakers. Each beaker contained $1 \mathrm{~kg}$ contaminated and moistened S1 or S2. The beakers were covered with wet filter paper and kept in the dark at $22 \pm 2{ }^{\circ} \mathrm{C}$. The earthworms were not fed during the experiments. After a given time interval the earthworms were removed, rinsed with water, and placed in wet filter paper for $24 \mathrm{~h}$ to allow the gut to empty. A $24-\mathrm{h}$ period of depuration was chosen because this was sufficiently long for all soils to be eliminated from the worms (Belfroid et al., 1994). Then the earthworms were rinsed with water again and stored at $-20^{\circ} \mathrm{C}$ for analysis.

Experiment 2. The effect of phthalates concentrations in soil on their bioavailability and the feasibility of mild chemical extraction for assessing bioavailability of phthalates in soil. Based on the results of Experiment 1, an exposure time of 15 days was selected to assess the near equilibrium relationship between the concentrations of phthalates in soils and those in earthworms. Phthalates were added to give final concentrations of $5.0,10.0,20.0,40.0$ and $50.0 \mathrm{mg} \mathrm{kg}^{-1}$ in dry soil. For each concentration in soil, 10 earthworms were used to determine the concentration in earthworms. Four replicates were carried out for each concentration point. The culture conditions of earthworms were the same as those in Experiment 1.

In our study we tested whether the methanol and methanol-water (1:1) extraction methods, which were often selected by others (Kelsey et al., 1997b), were feasible for assessing the bioavailability of phthalates in soils. After the spiked soils were incubated in the dark at $22 \pm 2{ }^{\circ} \mathrm{C}$ for 15 days, $3 \mathrm{~g}$ soil at each concentration level was transferred to a $50-\mathrm{ml}$ glass centrifuge tube to which $30 \mathrm{ml}$ of methanol or methanol-water (1:1) was added. The mixture was shaken on a reciprocating shaker for $24 \mathrm{~h}$ and the resulting slurry was then passed through a $0.25-\mu \mathrm{m}$ nylon filter. A portion of $20 \mathrm{ml}$ filtered solvent was extracted three times by $30 \mathrm{ml}$ hexane. The extract was reduced to $0.5 \mathrm{ml}$ by rotary evaporation prior to gas chromatographic analysis.

Experiment 3. The effect of aging on the extractability and bioavailability of phthalates in soil. S1, spiked with $20 \mathrm{~m} \mathrm{~kg}^{-1}$ of phthalates, was incubated in the dark at $22 \pm 2{ }^{\circ} \mathrm{C}$ for 100 and for 440 days. Then, the earthworms were incubated in the soil and kept for 15 days. The culture conditions of earthworms were the same as those in Experiment 1. In the meantime, subsamples of soil were extracted by Soxhlet, methanol, or methanol-water (1:1) extraction methods. The extraction conditions were the same as those described above.

\subsection{Determination of phthalates}

Standards of DNOP, DEHP, DEP, DBP, and DMP were purchased from AccuStandard Inc (New Haven, CT, USA). All reagents used were of pesticide grade.

The frozen earthworm (ca. $2.5 \mathrm{~g}$ ) or $2 \mathrm{~g}$ of soil was ground with $10 \mathrm{~g}$ of anhydrous $\mathrm{Na}_{2} \mathrm{SO}_{4}$ in a mortar and pestle prior to Soxhlet extraction. The ground mixture was placed in a thimble filter and extracted with $100 \mathrm{ml}$ mixture of hexane and dichloromethane (1:1) for $24 \mathrm{~h}$ at 5-6 min cycle ${ }^{-1}$. The extract was carefully concentrated to $2 \mathrm{ml}$ by rotary evaporator. The residue was transferred to a column $(1 \mathrm{~cm}$ i.d. $\times 10 \mathrm{~cm})$ packed with silica gel (60-80 mesh), covered by $2-\mathrm{cm}$ layer of sodium sulfate, which was used to clean up the extracts. Then, the column was washed with $30 \mathrm{ml}$ hexane and $30 \mathrm{ml}$ dichloromethane. The eluate was reduced to an adequate volume by rotary evaporator for analysis. The concentrations of phthalates were analyzed using a gas chromatograph equipped with an electron capture detector (Hewlett-Packard 6890, USA) and a HP-5 fused silica capillary column (film $0.32 \mu \mathrm{m}$, i.d. $0.25 \mathrm{~mm}$, length $30 \mathrm{~m})(\mathrm{J} \& \mathrm{~W}$, USA). The details of the analytical method were reported in our previous work (Hu et al., 2003). The detection limits of DMP, DEP, DBP, DEHP, and DNOP are 12.51, 11.48, 10.29, 6.14, and $7.56 \mu \mathrm{g} \mathrm{kg}^{-1}$, respectively.

\subsection{Equilibrium partitioning model}

The uptake kinetics of phthalates from spiked S1 and S2 by the earthworms (E. fetida) is described using the equilibrium partitioning model and both uptake and elimination are considered to follow a first order kinetics:

$\frac{\mathrm{d} C_{\mathrm{worm}}}{\mathrm{d} t}=k_{\mathrm{u}} C_{\text {soil }}-k_{\mathrm{e}} C_{\text {worm }}$,

which can be expressed after integration as

$C_{\text {worm }}=\frac{k_{\mathrm{u}}}{k_{\mathrm{e}}} C_{\text {soil }}\left(1-\mathrm{e}^{-k_{\mathrm{e}} t}\right)+C_{\text {worm }, 0} \mathrm{e}^{-k_{\mathrm{e}} t}$,

where $C_{\text {worm }}$ is the concentration of phthalates in earthworms on a wet-weight base and $C_{\mathrm{worm}, 0}$ is the initial phthalate concentration in earthworms kept in the "storing soil." $C_{\text {soil }}$ is the concentration of phthalates in soil on a dry-weight base, which is considered constant, because the uptake of phthalates by earthworms results in only a negligible reduction of their concentrations in soil. $k_{\mathrm{u}}$ is the uptake rate constant $\left(\mathrm{d}^{-1}\right) . k_{\mathrm{e}}$ is the elimination rate constant $\left(\mathrm{d}^{-1}\right)$. Elimination includes desorption to the surrounding solution, losses due to excretion, and metabolic transformation.

At equilibrium $\mathrm{d} C_{\mathrm{worm}} / \mathrm{d} t=0$, Eq. (2) results in a simple partitioning of compounds between soil and 
earthworms:

$\frac{k_{\mathrm{u}}}{k_{\mathrm{e}}}=\frac{C_{\text {worm }}}{C_{\text {soil }}}=$ BSAF

The ratio $C_{\text {worm }} / C_{\text {soil }}$ is also defined as biota-to-soil accumulation factor (BSAF) at steady state conditions (Belfroid et al., 1996).

\subsection{Data analysis}

All statistical analyses were conducted with the software SPSS 11.5 for Windows (SPSS Inc., Chicago, IL, USA). One-sample $t$ test was employed to compare the mean of a sample to a population mean, one-way ANOVA was used to assess the significance of the difference between groups, and linear regression analyses were conducted by the least-squares method. The curve of uptake kinetics was fitted to the equilibrium partitioning model using the nonlinear regression module of SPSS and the Levenberg-Marquardt method was used to determine the best estimates of parameters for the uptake kinetic curve. Statements of significant differences are based on $P \leqslant 0.05$.

\section{Results and discussion}

\subsection{Soil properties and spiking of phthalates to soils}

The properties of agricultural and forest soils (S1 and $\mathrm{S} 2)$ are given in Table 1. The difference in organic matter (OM) contents in $\mathrm{S} 1$ and $\mathrm{S} 2$ was obvious. The OM content of S2 $(4.53 \%)$ was higher than that of S1 $(1.35 \%)$. Since phthalates are ubiquitous in the environment, it is difficult to find soil without any phthalates. The concentrations of phthalates in $\mathrm{S} 1$ were relatively lower than those in S2 (Table 1). Therefore, S1 was selected as the storage soil. When earthworms were exposed to S1 only DBP was detected in earthworms, and its concentration was $0.06 \pm 0.02 \mathrm{mg} \mathrm{kg}^{-1}$. The concentrations of other phthalates in earthworms were lower than the detection limits.

In this study, different amounts of phthalates were spiked to S1 and S2. The maximum spiked amount was $50 \mathrm{mg} \mathrm{kg}^{-1}$. Although this amount was higher than that in arable soils in China (Hu et al., 2003), it was equivalent to that in the polluted soils (Rugge and Ahlert, 1992). The phthalates in artificially contaminated soils (S1 and S2) were determined after spiking. The average recoveries ranged $95-102 \%$, showing the accuracy and homogeneity of the spiking. After aging for different periods from 15 to 440 days, the recoveries of phthalates in spiked soils were found to be in the range $87-109 \%$, indicating that microbial degradation and volatilization during the aging time were negligible. During the accumulation experiments (Experiments 1-3), no mortality was observed and the average weight of earthworms was constant.

\subsection{Uptake of phthalates in soils to earthworms and the validity of the equilibrium partitioning model}

In Experiment 1, earthworms were exposed to two artificially contaminated soils at $5 \mathrm{mg} \mathrm{kg}^{-1}$ on dryweight basis for 5, 10, 15, 20, and 30 days. Two of five test compounds, DBP and DEHP, were detected in earthworms exposed to the spiked $\mathrm{S} 1$ and $\mathrm{S} 2$. The concentrations of DBP and DEHP in earthworms increased rapidly from 0 to 10 days and then remained almost constant during the rest of the experimental
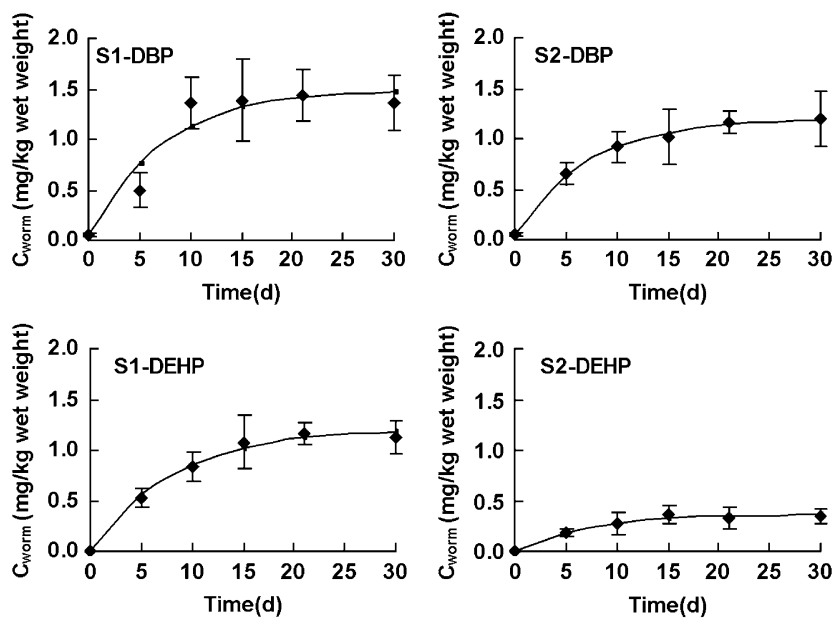

Fig. 1. Uptake curves of DBP and DEPH by earthworms exposed to the spiked $\mathrm{S} 1$ and $\mathrm{S} 2$ (mean $\pm \mathrm{SD}$ ). Data points: experimental values: Solid line: equilibrium partitioning model fitting.

Table 1

Physiochemical properties of soils

\begin{tabular}{|c|c|c|c|c|c|c|c|c|c|c|c|}
\hline \multirow[t]{2}{*}{ Soil } & \multirow{2}{*}{$\begin{array}{l}\text { Sand } \\
(\%)\end{array}$} & \multirow{2}{*}{$\begin{array}{l}\text { Silt } \\
(\%)\end{array}$} & \multirow{2}{*}{$\begin{array}{l}\text { Clay } \\
(\%)\end{array}$} & \multirow{2}{*}{$\begin{array}{l}\text { Organic matter } \\
(\%)\end{array}$} & \multirow[t]{2}{*}{$\mathrm{pH}$} & \multirow{2}{*}{$\begin{array}{l}\text { CEC } \\
\left(\mathrm{cmol} \mathrm{kg}^{-1}\right)\end{array}$} & \multicolumn{5}{|c|}{ Phthalates $\left(\mathrm{mg} \mathrm{kg}^{-1}\right)$} \\
\hline & & & & & & & DMP & DEP & DBP & DEHP & DNOP \\
\hline $\mathrm{S} 1$ & 36.02 & 56.43 & 6.44 & 1.35 & 8.28 & 34.25 & $\mathrm{ND}^{\mathrm{a}}$ & $0.26 \pm 0.04$ & $0.27 \pm 0.08$ & $0.06 \pm 0.01$ & ND \\
\hline $\mathrm{S} 2$ & 31.91 & 60.55 & 6.84 & 4.53 & 7.58 & 36.57 & $0.14 \pm 0.05$ & $0.45 \pm 0.13$ & $0.44 \pm 0.08$ & $0.12 \pm 0.03$ & ND \\
\hline
\end{tabular}

${ }^{\mathrm{a}} \mathrm{ND}$, not detected. 
period of 20 days (Fig. 1). To check the validity of the equilibrium partitioning model, we investigated whether the uptake curves of DBP and DEHP assimilated by earthworms exposed to spiked $\mathrm{S} 1$ and $\mathrm{S} 2$ could be described by Eq. (2). Good fits were obtained between the experimental data and Eq. (2) calculation for two soils. The correlation coefficients were in the range 0.709-0.864 (Table 2), indicating that the equilibrium partitioning model was valid. The fitted parameters $k_{\mathrm{u}}$ and $k_{\mathrm{e}}$ are shown in Table 2. The BSAFs calculated as the ratio of $k_{\mathrm{u}}$ to $k_{\mathrm{e}}$, derived from the equilibrium partitioning model, are also listed in Table 2.

To deduce the exposure time necessary to reach approximate equilibrium concentrations of DBP and DEHP in earthworms, we calculated theoretical steady state concentrations using Eq. (3) and compared them to the concentrations at time steps 10,15 , and 20 days calculated from Eq. (2). After 10 days of exposure in spiked S1 the calculated concentrations of DBP and DEHP in earthworms were on the average of $75 \%$ of the theoretical steady state concentrations for DBP and $72 \%$ for DEHP. After 15 days of exposure, respective percentages were 94\% (DBP) and 95\% (DEHP); after 20 days the corresponding percentages were $96 \%$ (DBP) and $96 \%$ (DEHP), respectively. The calculated concentrations of DBP and DEHP in earthworms exposed to S2 for 15 days were $94 \%$ (DBP) and 93\% (DEHP) of the theoretical steady state concentrations, respectively. Therefore, we supposed that the assumption of steady state conditions after 15 days of exposure was valid and we selected an exposure time of 15 days in the following experiments.

When the concentrations of DBP and DEHP in soils were $5 \mathrm{mg} \mathrm{kg}^{-1}$, the mean steady state concentrations in earthworms were $1.39 \pm 0.41$ and $1.06 \pm 0.27 \mathrm{mg} \mathrm{kg}^{-1}$ for DBP and DEHP, respectively, in spiked S1, while those in spiked $\mathrm{S} 2$ were $1.02 \pm 0.32$ and $0.36 \pm 0.11 \mathrm{mg} \mathrm{kg}^{-1}$ for DBP and DEHP, respectively. The difference in steady state concentrations in DBP and DEHP in earthworms was significant $(P<0.05)$, although their concentrations in $\mathrm{S} 1$ and $\mathrm{S} 2$ were approximately the same. The steady state concentration of DBP in earthworms was higher than that of DEHP in both spiked S1 and S2. The steady state concentrations of DBP and DEHP in earthworms exposed to the spiked S1 were higher than those in the spiked S2.

The differences in bioavailability in the five phthalates could be explained by their behavior in soil and their uptake kinetics in earthworms. More hydrophobic compounds, such as DNOP, in soil were more slowly assimilated by earthworms because they had higher affinity for soil OM, which caused their desorption and diffusion to be too slow to replenish the soil solution (Landrum, 1989). With decreasing concentration of compounds in soil solution, the uptake of compounds by earthworms via dermis decreased and subsequently the concentration of compounds in earthworms decreased. However, more hydrophobic compounds were more easily taken via passive diffusion from the soil solution through the outer lipid membrane of earthworms (Krauss et al., 2000). Therefore, the bioavailability of soil-associated compounds to earthworms cannot be completely explained by their octanol-water partition coefficients $\left(K_{\mathrm{ow}}\right)$ and was simultaneously influenced by various factors such as the characteristics of the given compound, the soil, and the organism's toxicokinetics. Many people tried to assess the relationship between the bioavailability of organic pollutants in soils and their $K_{\text {ow }}$, although the BSAF is expected to be independent of $K_{\text {ow }}$ according to its conception (Sijm et al., 2000; Krauss et al., 2000). For the phthalate congeners that we studied, the undetectable DMP and DEP in earthworms may be due to their higher metabolic degradation. In in vitro studies on metabolism of phthalate congeners it had been demonstrated that the lower the molecular weight of phthalate ester the faster the rate of metabolism (The Royal Society of Chemistry, 1981), although there was no information on the metabolic degradation of phthalates by earthworms. For undetectable DNOP, the most likely explanations were a strong sorption and a considerably slower desorption rate (Swann et al., 1983), which was not sufficient to replenish the solution phase depleted by the earthworm uptake. This effect was also observed for some pesticides (Curl et al., 1987; Lord et al., 1980). The difference in steady state concentrations of DBP and DEHP in earthworms exposed to spiked S1 and S2

Table 2

Toxicokinetic parameters of the equilibrium partitioning model for DBP and DEHP in soils

\begin{tabular}{llllll}
\hline Soils & Phthalates & $R$ & $k_{\mathrm{u}}\left(\mathrm{d}^{-1}\right)^{\mathrm{a}}$ & $k_{\mathrm{e}}\left(\mathrm{d}^{-1}\right)^{\mathrm{a}}$ & $\mathrm{BSAF}=k_{\mathrm{u}} / k_{\mathrm{e}}$ \\
\hline S1 & DBP & 0.776 & $0.041(0.028-0.059)^{\mathrm{a}}$ & $0.136(0.080-0.212)$ & 0.307 \\
& DEHP & 0.861 & $0.030(0.225-0.036)$ & $0.123(0.083-0.159)$ & 0.244 \\
S2 & DBP & 0.864 & $0.033(0.024-0.044)$ & $0.138(0.089-0.191)$ & 0.242 \\
& DEHP & 0.709 & $0.010(0.006-0.015)$ & $0.130(0.072-0.233)$ & 0.073 \\
\hline
\end{tabular}

${ }^{\mathrm{a}} 95 \%$ confidence limits. 
might be due to different soil properties of agricultural and forest soils. Higher organic matter in S2 led to less phthalates desorption and lower BSAF of DBP and DEHP in S2.

In our experiments, BSAFs were calculated by two methods; one was the ratio $k_{\mathrm{u}} / k_{\mathrm{e}}$, and the other was $C_{\text {worm }} / C_{\text {soil }}$. Because the BSAFs for each compound and soil calculated from $k_{\mathrm{u}}$ and $k_{\mathrm{e}}$ are single, we considered BSAF the population mean. There were six replicates of the BSAFs calculated from $C_{\text {worm }} / C_{\text {soil }}$ for each compound and soil, and the six replicates were considered a sample. One-sample $t$ test was employed to investigate whether there is statistical difference between the BSAFs calculated by the two methods, and it was found that there was no significant difference in BSAFs calculated by the two methods $(P>0.05)$, which further manifested the validity of the equilibrium partitioning theory to describe uptake kinetics of soil-associated DBP and DEHP in earthworms.

Although the steady state conditions were reached after 15 days of exposure, slight decreases in the concentrations of DBP and DEHP in earthworms were found between residence times of 20 and 30 days in contaminated S1 and S2. Quite similar phenomena were observed by many other researchers for other organic chemicals (Krauss et al., 2000). Such differences were ascribed to the earthworms habits of living mainly in permanent burrows, and the surrounding soil solution may have been depleted of DBP and DEHP during the longer exposure time as a result of continuous uptake by the earthworms. The desorption and diffusion might be too slow to replenish the solution; therefore, the decreasing uptake amount resulted in decreasing con- centrations in earthworm tissue at longer exposure times.

\subsection{The effect of concentrations of phthalates in soil on} their bioavailability and the feasibility of mild chemical extraction for predicting bioavailability of phthalates in soil

According to Eq. (3) there should be a simple linear partitioning relationship between $C_{\text {worm }}$ and $C_{\text {soil }}$ at steady state conditions.

To test this hypothesis, earthworms were exposed to soils receiving $5.0,10.0,20.0,40.0$, and $50.0 \mathrm{mg} \mathrm{kg}^{-1}$ test compounds for 15 days. Then the steady state concentrations of test compounds in earthworms were determined (Table 3). Subsequently, we conducted a linear regression analysis of $\log C_{\text {worm }}$ versus $\log C_{\text {soil }}$. The resulting regression equation was

$\log C_{\text {worm }}=s \log C_{\text {soil }}+\log$ BSAF.

If Eq. (4) was expanded with a nonlinearity parameter $s$ (Krauss et al., 2000),

$C_{\text {worm }}=\operatorname{BSAF}\left(C_{\text {soil }}\right)^{s}$.

Regression analyses showed significant relationship between $\log C_{\text {soil }}$ and $\log C_{\text {worm }}$ with $r=0.993-0.999$. The parameters of $s$ were 1.05 (DBP) and 0.77 (DEHP) in spiked S1 and 1.05 (DBP) and 0.94 (DEHP) in spiked S2. If $s$ was about 1 , the assumption of simple partitioning was met, i.e., a partitioning of DBP and DEHP between soils and lipid-rich earthworms.

The BSAFs of earthworms exposed to different concentrations of DBP and DEHP in soils are also

Table 3

Effect of DBP and DEHP concentrations in soils on their bioavailability to earthworms (mean \pm SD)

\begin{tabular}{|c|c|c|c|c|c|}
\hline \multirow[t]{2}{*}{ Soils } & \multirow{2}{*}{$\begin{array}{l}C_{\text {soil }} \\
\left(\mathrm{mg} \mathrm{kg}^{-1}\right)\end{array}$} & \multicolumn{2}{|l|}{ DBP } & \multicolumn{2}{|l|}{ DEHP } \\
\hline & & $C_{\text {worm }}\left(\mathrm{mg} \mathrm{kg}^{-1}\right)$ & BSAF & $C_{\text {worm }}\left(\mathrm{mg} \mathrm{kg}^{-1}\right)$ & BSAF \\
\hline \multirow[t]{7}{*}{ S1 } & 5 & $1.39 \pm 0.41^{\mathrm{a}}$ & $0.28 \pm 0.08$ & $1.06 \pm 0.27$ & $0.21 \pm 0.05$ \\
\hline & 10 & $2.26 \pm 0.21$ & $0.23 \pm 0.02$ & $2.02 \pm 0.12$ & $0.20 \pm 0.04$ \\
\hline & 20 & $5.07 \pm 1.67$ & $0.25 \pm 0.08$ & $3.43 \pm 0.61$ & $0.17 \pm 0.03$ \\
\hline & 40 & $11.21 \pm 3.06$ & $0.28 \pm 0.08$ & $5.61 \pm 0.85$ & $0.14 \pm 0.02$ \\
\hline & 50 & $15.14 \pm 5.52$ & $0.30 \pm 0.11$ & $6.53 \pm 1.53$ & $0.13 \pm 0.03$ \\
\hline & $r$ & 0.995 & & 0.999 & \\
\hline & $\mathrm{s}$ & $1.05(0.84-1.27)^{\mathrm{b}}$ & & $0.77(0.68-0.88)$ & \\
\hline \multirow[t]{7}{*}{ S2 } & 5 & $1.02 \pm 0.32$ & $0.20 \pm 0.06$ & $0.36 \pm 0.11$ & $0.07 \pm 0.02$ \\
\hline & 10 & $1.81 \pm 0.32$ & $0.18 \pm 0.03$ & $0.84 \pm 0.27$ & $0.08 \pm 0.03$ \\
\hline & 20 & $4.17 \pm 1.52$ & $0.21 \pm 0.08$ & $1.21 \pm 0.23$ & $0.06 \pm 0.01$ \\
\hline & 40 & $8.31 \pm 2.41$ & $0.21 \pm 0.06$ & $2.75 \pm 0.61$ & $0.07 \pm 0.02$ \\
\hline & 50 & $11.40 \pm 4.42$ & $0.23 \pm 0.09$ & $3.31 \pm 0.54$ & $0.07 \pm 0.01$ \\
\hline & $r$ & 0.998 & & 0.993 & \\
\hline & $\mathrm{s}$ & $1.05(0.92-1.18)$ & & $0.94(0.73-0.14)$ & \\
\hline
\end{tabular}

${ }^{\mathrm{a}}$ The $C_{\text {worm }}$ values were determined after 15-day incubation.

${ }^{\mathrm{b}} 95 \%$ confidence limits. 
shown in Table 3. BSAFs of DBP and DEHP at five different soil concentrations were insignificantly different from each other $(P>0.05)$, which demonstrated that the concentrations of DBP and DEHP in soils had no effect on their BSAFs.

The results of mild chemical extraction showed that there was different extractability of DBP and DEHP from soil by different solvents (Fig. 2). The average percentages extracted from S1 with methanol were $74.9 \%$ and $101.8 \%$ of total soil concentrations of DBP and DEHP, respectively. The average methanol extractable percentages were $44 \%$ (DBP) and 63\% (DEHP) for S2. The extractable percentages by methanol increased linearly with increasing $\log K_{\mathrm{OW}}$ for phthalates. However, methanol-water (1:1) could extract more than $80 \%$ of all test compounds in soil and the extractable percentages were independent of their $\log K_{\text {Ow }}$. Correlation analysis was also made between the bioassay and the nonexhaustive chemical extraction, and the results are shown in Fig. 2. The methanolextractable concentrations of DBP and DEHP were closely correlated with their concentrations in earthworms (DBP: $r=0.949$; DEHP: $r=0.938$ ). The correlation coefficients between methanol-water (1:1)extractable concentrations of DBP and DEHP and their concentrations in earthworms were 0.946 and 0.890 , respectively. The correlation coefficients did not differ from those between total soil concentrations and concentrations in earthworms (Table 3).

\subsection{The effect of aging on the extractability and bioavailability of phthalates in soil}

The aging effect often refers to the phenomenon that with increased residence time the extractability and bioavailability of organic compounds in soil decrease (Sijm et al., 2000; Alexander, 2000). Therefore, to properly understand the chemical behavior and bioavailability of organic compounds in soil, the aging effect must be considered.

The data in Table 4 represent the percentage recoveries of the amounts initially added. With increasing age of soil, the concentration of DBP in earthworms decreased to $82 \%$ of the steady state concentration in earthworms exposed to unaged soil after 100-day incubation and $68 \%$ after 440-day incubation, while for DEHP it decreased to $83 \%$ and $61 \%$ for 100 and 440-day incubation, respectively. However, the recoveries of DBP and DEHP by Soxhlet extraction appeared to decline only slightly with prolonged aging time, but the small decreases were statistically insignificant $(P>0.05)$, which indicated that the Soxhlet extraction was not suitable for assessing the bioavailability of aged phthalates in soil. The percentage of phthalates
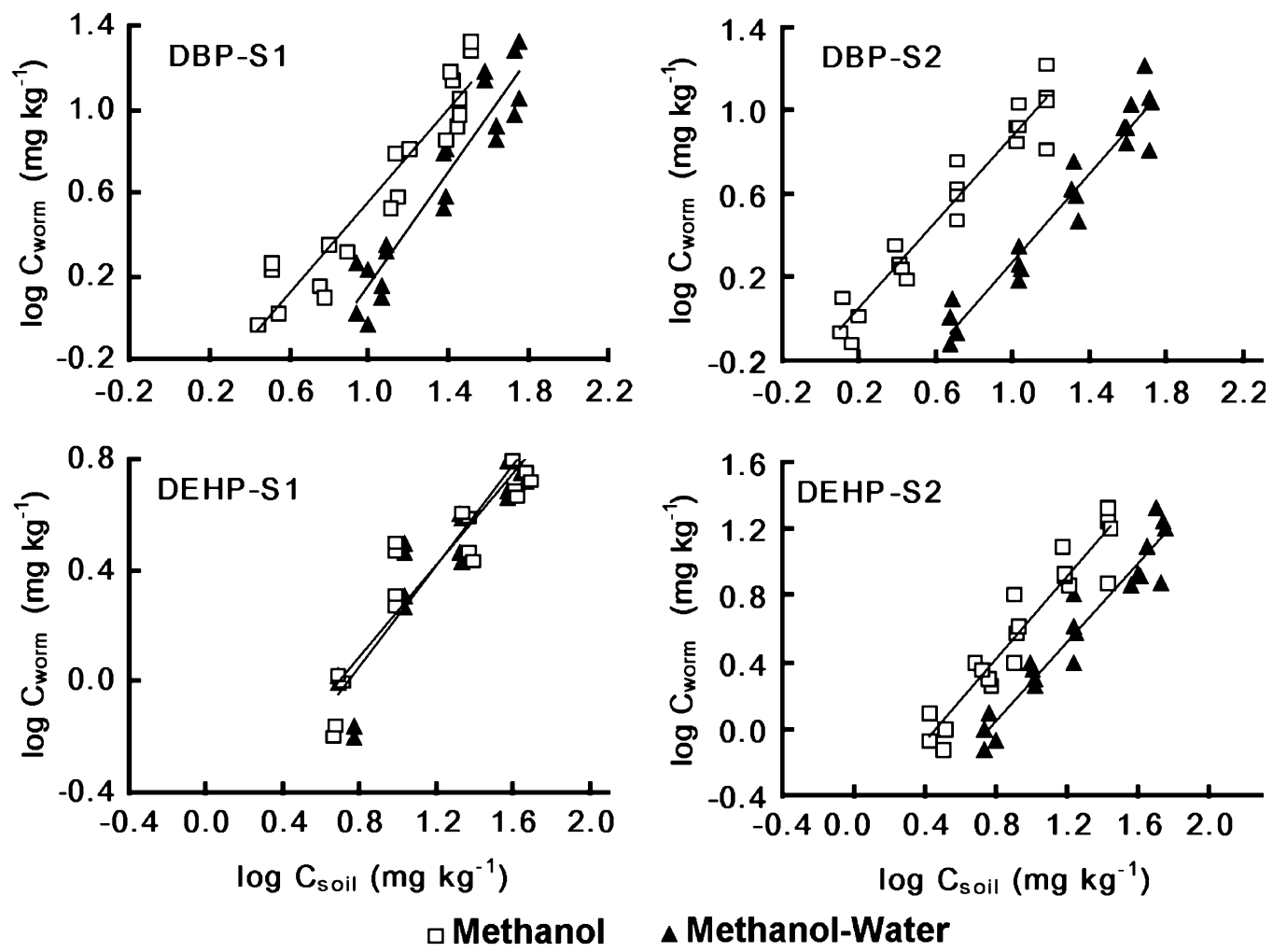

Fig. 2. Relationship between the concentrations of DBP and DEHP in earthworms exposed to the spike S1 and S2 and that extracted with mild chemical extractions. 
Table 4

Influence of aging time of DBP and DEHP in S1 on their extractability and availability to earthworms

\begin{tabular}{llllll}
\hline \multirow{2}{*}{ Compounds } & Aging time (day) & \multicolumn{2}{l}{ Extracted by various methods (\%) } & Assimilated by worms (\%) \\
\cline { 3 - 5 } & & Soxhlet & Methanol-water & Methanol & \\
\hline DBP & 15 & $101.9 \mathrm{~A}^{\mathrm{a}}$ & $102.4 \mathrm{~A}$ & $61.1 \mathrm{~A}$ & $30.2 \mathrm{~A}$ \\
& 100 & $99.0 \mathrm{~A}$ & $100.7 \mathrm{~A}$ & $50.2 \mathrm{~B}$ & $24.7 \mathrm{~B}$ \\
& 440 & $95.2 \mathrm{~A}$ & $94.7 \mathrm{~B}$ & $41.3 \mathrm{C}$ & $20.4 \mathrm{C}$ \\
DEHP & 15 & $102.0 \mathrm{~A}$ & $101.9 \mathrm{~A}$ & $95.2 \mathrm{~A}$ & $13.5 \mathrm{~A}$ \\
& 100 & $100.7 \mathrm{~A}$ & $98.8 \mathrm{~A}$ & $79.5 \mathrm{~B}$ & $11.3 \mathrm{~B}$ \\
& 440 & $100.9 \mathrm{~A}$ & $92.2 \mathrm{~B}$ & $57.9 \mathrm{C}$ & $8.2 \mathrm{C}$ \\
\hline
\end{tabular}

${ }^{\mathrm{a}}$ Values in the columns for the same compound followed by the same letter are not statistically different $(P>0.05)$.

extracted by methanol-water (1:1) after 100-day incubation did not change significantly $(P>0.05)$. However, after 440-day incubation, the extractability decreased obviously $(P<0.05)$. Simultaneously, with increasing aging time, the extractable DBP by the methanol extraction method decreased to $82 \%$ and $68 \%$ after 100 - and 440-day incubation, while the extractable DEHP decreased to $83 \%$ and $61 \%$, respectively. These decline rates were consistent with those of earthworm assimilation. Our results revealed that the Soxhlet and methanol-water $(1: 1)$ extractions would lead to overestimation of the risk of aged DBP and DEHP in soils. Methanol extraction was the best predictor for approximating the bioavailability of phthalates to earthworms.

\section{Conclusions}

Among the five phthalates studied, only DBP and DEHP were detected in earthworms. DBP and DEHP had high BSAFs, which indicated that these compounds were more easily available to earthworms. Therefore, DBP and DEHP could be accumulated more readily through the food chain and pose greater threats to ecosystems and human health. Soil concentrations of DBP and DEHP had no significant effects on their corresponding BSAFs. Based on the statistical analysis, the uptake kinetics of phthalates in lab-contaminated soil by earthworms could be well described by the equilibrium partitioning model. With increased aging time, the extractability and bioavailability of phthalates decreased. Compared with the Soxhlet and the methanol-water (1:1) extraction methods, the methanol extraction method was preferred for its ability to predict the bioavailability of DBP and DEHP in soils. Nevertheless, the data represent merely the results of a feasibility study since there were only two soils, two compounds, and one species of test organism. More soils and organisms with different characteristics will be included in our future work.

\section{Acknowledgments}

This work was supported by the Chinese Academy of Sciences under Grant KZCX2-414 and the National Natural Science Foundation of China (Grants: 20377048 and 20237010).

\section{References}

Alexander, M., 2000. Aging, bioavailability, and overestimation of risk from environmental pollutants. Environ. Sci. Technol. 34, 4259-4265.

Anderson, W.C., Loehr, R.C., Smith, B.P., 1999. Environmental availability of chlorinated organics, explosives, and metals in soils, American Academy of Environmental Engineers. Annapolis, 35-84.

Belfroid, A.C., Sikkenk, M., Seinen, W., van Gestel, C.A.M., Hermens, J., 1994. The toxicokinetic behavior of chlorobenzenes in earthworm (Eisenia andrei): experiments in soil. Environ. Toxicol. Chem. 13, 93-99.

Belfroid, A.C., Sijm, D.T.H.M., Van Gestel, C.A.M., 1996. Bioavailability and toxicokinetics of hydrophobic aromatic compounds in benthic and terrestrial invertebrates. Environ. Rev. 4, 276-299.

Connell, D.W., Markwell, R.D., 1990. Bioaccumulation in the soil to earthworm system. Chemosphere 20, 91-100.

Curl, E.A., Edwards, P.J., Elliott, C., Leahey, J.P., 1987. The conjugation and accumulation of metabolites of cypermethrin by earthworms. Pestic. Sci. 20, 207-222.

DiToro, D.M., Zarba, C., Hansen, D.J., Berry, W., 1991. Technical basis for establishing sediment quality criteria for non-organic chemicals using equilibrium partitioning. Environ. Toxicol. Chem. 11, 1541-1583.

Environmental Protection Agency (EPA), Environmental Protection Office of Science and Franke Technology, 2002. National Recommended Water Quality Criteria, 2002, United States Office of Water EPA-822-R-02-047, November.

Hu, X., Wen, B., Shan, X., 2003. Survey of phthalate pollution in arable soils in China. J. Environ. Monit. 5, 649-653.

Kelsey, J.W., Alexander, M., 1997. Declining bioavailability and inappropriate estimation of risk of persistent compounds. Environ. Toxicol. Chem. 16, 582-585.

Kelsey, J.W., Kottler, B.D., Alexander, M., 1997. Selective chemical extractants to predict bioavailability of soil-aged organic chemicals. Environ. Sci. Technol. 31, 214-217. 
Krauss, M., Wilcke, W., Zech, W., 2000. Availability of polycyclic aromatic hydrocarbons (PAHs) and polychlorinated biphenyls (PCBs) to earthworms in urban soils. Environ. Sci. Technol. 34, 4335-4340.

Lanno, R.P., Wells, J., Conder, J., Bradham, K.D., Basta, N.T., 2004. The bioavailability of chemicals in soil for earthworms. Ecotoxicol. Environ. Saf. 57 (1), 39-47.

Landrum, P.F., 1989. Bioavailability and toxicokinetics of polycyclic aromatic hydrocarbons sorbed to sediments for the amphipod Pontoporeia hoyi. Environ. Sci. Technol. 23, 588-595.

Lord, K.A., Briggs, G.G., Neale, M.C., Manlove, R., 1980. Uptake of pesticides from water and soil by earthworms. Pestic. Sci. 11, 401-408.

Morrison, D.E., Robertson, B.K., Alexander, M., 2000. Bioavailability to earthworms of aged DDT, DDE, DDD, and dieldrin in soil. Environ. Sci. Technol. 34, 709-713.

Nam, K., Chung, N., Alexander, M., 1998. Relationship between organic matter content of soil and the sequestration of phenanthrene. Environ. Sci. Technol. 32, 3785-3788.

Nelson, D.W., Sommers, L.E., 1982. Total carbon, organic carbon, and organic matter. In: Page, A.L., et al. (Eds.), Methods of soil analysis: Part 2, second ed. ASA and SSSA, Madison, WI, pp. 539-579.

Organisation for Economic Co-operation and Development (OECD), 1984. Guidelines for Testing of Chemicals. Section 2, Effects on Biotic Systems, Earthworm acute toxicity tests, Paris, France.

Rhoades, J.D., 1982. Cation exchange capacity. In: Page, A.L. (Ed.), Methods of Soil Analysis, Part 2 Chemical and microbiological properties, second ed. Agronomy 9, 149-157.
Rugge, C.D., Ahlert, R.C., 1992. Ground and aerial survey of a peninsular landfill. Water Res. 26, 519-526.

Shea, D., 1989. Developing national sediment quality criteria. Environ. Sci. Technol. 22, 1256-1261.

Sijm, D., Kraaij, R., Belforoid, A., 2000. Bioavailability in soil or sediment: exposure of different organisms and approaches to study it. Environ. Pollut. 108, 113-119.

Staples, C.A., Peterson, D.R., Parkerton, T.F., Adams, W.J., 1997. The environmental fate of phthalate esters: a literature review. Chemosphere 35, 667-749.

Swann, R.L., Laskowski, D.A., McCall, P.J., Vander Kuy, K., Dishburger, H.J., 1983. A rapid method for the estimation of the environmental parameters octanol/water partition coefficient, soil sorption constant, water to air ratio, and water solubility. Res. Rev. 85, 17-28.

Tang, J., Robertson, B.K., Alexander, M., 1999. Chemical extraction methods to estimate bioavailability of DDT, DDE, and DDD in soil. Environ. Sci. Technol. 33, 4346-4351.

The Royal Society of Chemistry, 1981. Foreign Compound Metabolism in Mammals. Volume 6: A Review of the Literature Published during 1978 and 1979. The Royal Society of Chemistry, London, p. 340

Wezel, A.P., van Vlaardingen, P., Posthumus, R., Crommentuijn, G.H., Sijm, D.T.H.M., 2000. Environmental risk limits for two phthalates, with special emphasis on endocrine disruptive properties. Ecotoxicol. Environ. Saf. 46, 305-321. 